\title{
Trisubstituted
}

\section{Hexahydroimidazo[1,2- $\alpha]$ Pyridine 6 (TIP-6) as a Small-Molecule Inhibitor of Bcl-2 for Inhibition of Proliferation in Hepatoma Cells}

\author{
Wenchao Zhang1, Yanlong Pan ${ }^{1,2}$, Heng Zhou ${ }^{1}$, \\ Xiaofei Gao1,3, Jizu Song1, Yuexia Hua1, Yuping Du' ${ }^{1}$, \\ Jinbo Yang1, Xinping Hui ${ }^{4,5^{*}}$, Qin Wang ${ }^{*}$ \\ ${ }^{1}$ Institute of Cancer Biology and Drug Screening, School of Life Sciences, Lanzhou University, Lanzhou, China \\ ${ }^{2}$ Center of Scientific Experiment, Gansu University of Chinese Medicine, Lanzhou, China \\ ${ }^{3}$ State Key Laboratory of Applied Organic Chemistry, Lanzhou University, Lanzhou, China \\ ${ }^{4}$ College of Chemistry and Chemical Engineering, Lanzhou University, Lanzhou, China \\ ${ }^{5}$ Institute of Modern Physics, Chinese Academy of Sciences, Lanzhou, China \\ Email: *qwang@lzu.edu.cn, *huixp@lzu.edu.cn
}

How to cite this paper: Zhang, W.C., Pan, Y.L., Zhou, H., Gao, X.F., Song, J., Hua, Y.X., Du, Y.P., Yang, J.B., Hui, X.P. and Wang, Q. (2019) Trisubstituted Hexahydroimidazo[1,2- $\alpha$ ] Pyridine 6 (TIP-6) as a Small-Molecule Inhibitor of $\mathrm{Bcl}-2$ for Inhibition of Proliferation in Hepatoma Cells. Journal of Biosciences and Medicines, 7, 29-41.

https://doi.org/10.4236/jbm.2019.71004

Received: November 7, 2018

Accepted: January 1, 2019

Published: January 4, 2019

Copyright (๑) 2019 by author(s) and Scientific Research Publishing Inc. This work is licensed under the Creative Commons Attribution International License (CC BY 4.0).

http://creativecommons.org/licenses/by/4.0/

\section{(c) (i) Open Access}

\begin{abstract}
Background: Cancer poses a serious threat to human health and survival, and studies had been reported that imidazole or pyridine analogs play as an anti-cancer agent in cancer treatment. Meanwhile, Autophagy plays a dual and substantial role in maintaining cellular homeostasis in cancers, for it is either initiated to rescue cancer cells under stress or executed to promote autophagy cell death under certain circumstances. Objective: TIP-6 was designed and synthesized (7-(4-methoxyphenyl)-5,8 $\alpha$-diphenyl-1,2,3,7,8, $8 \alpha$-hexahyd-roimidazo[1,2- $\alpha$ ]pyridine-6) for evaluation of its biological effects on HepG2 cells and exploring the potential anti-cancer effect. Methods and Results: Chemical synthesis results indicated that the expected compound was obtained. The results of the MTT assay showed that TIP- 6 arrested the growth of HepG2 cells in G2/M phase in the cell cycle, showing significant anti-proliferation effect. And analysis of morphological changes and formation of acidic vesicular organelles showed that the autophagy was induced but not apoptosis. The results were further validated by the enhanced expression of LC3I/II, Beclin1and down-regulated expression of Bcl-2in western blot analysis. In addition, the molecular docking predicted that TIP-6 preferentially binds to $\mathrm{Bcl}-2$ and $\mathrm{Bcl}-\mathrm{xL}$ in the active sites. Conclusion: Overall, this study demonstrated that autophagy cell death was executed in HepG2 cells which were induced by TIP- 6 .
\end{abstract}




\section{Keywords}

TIP-6, Antiproliferative, Autophagy, Bcl-2, LC3, Docking

\section{Introduction}

Cancer is a disease involving abnormal cell growth, and inhibiting cell growth or promoting apoptosis which is a fundamental area of cancer research. At present, people try to select potential anticancer drugs from natural products or inorganic compounds. Many studies have shown that imidazole or pyridine analogs have significant anti-cancer effects.

Autophagy is a biological process ever evolved into eukaryotes to maintain the cytoplasmic homeostasis and found plays a tug-of-war game in either promoting cell survival or inducing cell death as a number of genes and proteins are identified and implicated in these two forces [1] [2] [3]. Although autophagy plays a crucial role in the mammalian development and differentiation [4] and evidenced in a wide range of diseases including cancer [5], the exact biological role of autophagy is still controversial, given that both a prosurvival role and a pro-death role of autophagy are proposed respectively [6]. A large body of evidence demonstrated that well-tuned autophagy is readily programmed for cell survival under physiological condition, while aberrant autophagy is eventually executed to facilitate cell death under pathologic conditions [7]. However, how does autophagy promote or suppress in diseases such as cancer and how autophagy can be biochemically regulated to treat cancer need to be further studied to understand the dual role of autophagy in cancer, thus providing potential novel cancer targets [8].

Drawing the picture in which how the autophagy is mechanistically regulated in cancer cells is further complicated by the observations of very different scenarios of autophagy modulations in both individual cancer cell types and the cancer development of different stages [9] [10] [11]. Since the autophagy is both constitutively activated and spatiotemporally regulated in a dynamic fashion, a dual role is frequently referred to autophagy in cancer for its being able to rescue cancer cells under stress and, when the apoptosis (Type I programmed cell death) is defective, for its being capable of promoting autophagy cell death (Type II programmed cell death). ATG gene family is principally related to autophagy [12] in yeast and oncogenes like PI3K/AKT, BCL2, Ras and tumor suppressor genes such as TSC1, TSC2, LKB1, PTEN, TP53, and Becn1 are found capable of inhibiting autophagy and inducing autophagy, respectively [13]. Furthermore, Bcl-2 is found both in vitro and in vivo to inhibit autophagy through its interaction with Beclin 1, the autophagy protein in mammalians [14] [15]. Apogossypolone (ApoG2), a small-molecule inhibitor of Bcl-2, is demonstrated to induce autophagy in prostate cancer cell line PC-3 and LNCaP cells [16].

Based on the above, this study was trying to design and synthesize a com- 
pound, which is an imidazole or pyridine analogs, for evaluation of its biological effects on HepG2 cells, a liver hepatocellular carcinoma. And preliminary tests results demonstrated that TIP-6 may induce autophagy with HepG2 cell line; this result led us to have the confidence to explore the underlying mechanism of TIP-6 executed autophagy with Hep2 cells.

\section{Materials and Methods}

\subsection{Synthesis of TIP-6}

The reaction was carried out under nitrogen atmosphere. 4-Methoxybenzaldehyde and acetophenone were purchased from Aldrich and used directly. ${ }^{1} \mathrm{H}$ and ${ }^{13} \mathrm{C}$ NMR spectra were recorded on a Mercury Plus 300BB (300 MHz) spectrometer. IR spectrum was recorded using Nicolet NEXUS 670 FT-IR instrument. HRMS was performed on Bruker Apex II mass instrument (ESI). Melting point was determined on an XT-4 melting point apparatus and was uncorrected. A solution of 4-methoxybenzaldehyde $(5 \mathrm{mM})$, acetophenone $(12.5 \mathrm{mM})$ and ethylenediamine $(5 \mathrm{mM})$ and $p$-toluenesulfonic acid $(1 \mathrm{mM})$ in methanol $(5 \mathrm{ml})$ was refluxed for $24 \mathrm{~h}$. The solvent was evaporated, and the residue was recrystallized from methanol to give the product TIP-6. Yield $80 \%$, white solid, m.p. $84.5^{\circ} \mathrm{C}$ $85.5^{\circ} \mathrm{C} .1 \mathrm{H} \mathrm{NMR}(300 \mathrm{MHz}, \mathrm{CDCl} 3) \delta: 1.85(\mathrm{t}, \mathrm{J}=12.3 \mathrm{~Hz}, 1 \mathrm{H}), 2.43(\mathrm{dd}, \mathrm{J}=$ 5.7, $11.7 \mathrm{~Hz}, 1 \mathrm{H}), 2.91-3.01(\mathrm{~m}, 2 \mathrm{H}), 3.05-3.20(\mathrm{~m}, 2 \mathrm{H}), 3.56-3.63(\mathrm{~m}, 1 \mathrm{H})$, $3.80(\mathrm{~s}, 3 \mathrm{H}), 4.96(\mathrm{~s}, 1 \mathrm{H}), 6.84(\mathrm{~d}, \mathrm{~J}=8.7 \mathrm{~Hz}, 2 \mathrm{H}), 7.17(\mathrm{~d}, \mathrm{~J}=9.0 \mathrm{~Hz}, 2 \mathrm{H}), 7.29$ $7.42(\mathrm{~m}, 6 \mathrm{H}), 7.64-7.70(\mathrm{~m}, 4 \mathrm{H}) .13 \mathrm{C} \mathrm{NMR}\left(75 \mathrm{MHz}, \mathrm{CDCl}_{3}\right) \delta: 38.25,41.56$, $44.13,52.21,55.23,80.62,107.90,113.75,125.86,127.10,127.43,127.84,128.21$, $128.27,128.33,137.38,139.59,144.76,145.47,157.99 . \mathrm{IR}(\mathrm{KBr}) v_{\max }: 3287,3057$, 2949, 2922, 2864, 2831, 1609, 1509, 1444, 1362, 1289, $1244 \mathrm{~cm}^{-1}$. HRMS (ESI): Exact mass calcd for $\mathrm{C}_{26} \mathrm{H}_{27} \mathrm{~N}_{2} \mathrm{O}(\mathrm{M}+\mathrm{H})+: 383.2118$, found: 383.2111 .

\subsection{Cell Culture}

Human tumor cell lines HepG2 and Hela were obtained from Biology Preservation Center of Shanghai Institute of Material Medical. The passage number is less than 10 when it was used for the experiments, and the institute states that mycoplasma testing is negative. Cells were cultured in DMEM medium (Gibco) supplemented with $10 \%$ fetal bovine serum (Lanzhou Minhai Biotech. Ltd.). 2 $\mathrm{mM} \mathrm{L}$-glutamine, $100 \mathrm{U} / \mathrm{ml}$ penicillin and $100 \mathrm{mg} / \mathrm{ml}$ streptomycin were added to the medium during incubation. And cells were incubated at $37^{\circ} \mathrm{C}$ in the humidified atmosphere of $5 \% \mathrm{CO}_{2}$ and $95 \%$ air.

\subsection{MTT Assay and Cell Cycle Analysis}

The effect of TIP- 6 on cell viability was determined by MTT assay. Cells were seeded in 96-well plate with $4 \times 10^{3}$ cells/well in $100 \mu \mathrm{l}$ medium and cultured for $12 \mathrm{~h}$ before treating with TIP- 6 at indicated concentrations $(0,20,40,60,80,160$ $\mu \mathrm{M})$. Cells were subsequently cultured for $24 \mathrm{~h}$. The medium was replaced by $100 \mu \mathrm{l}$ fresh medium containing $0.5 \mathrm{mg} / \mathrm{ml} \mathrm{MTT}$ and kept in the incubator for 4 
h. Then, the medium was removed carefully and $100 \mu \mathrm{D}$ DMSO was added to each well to dissolve the formazan crystals. The absorbance was measured by VICTOR Multilabel Reader (PerkinElmer, USA) at wavelength of $570 \mathrm{~nm}$. All the manipulations were carried out in triplicate. For cell cycle analysis, cells were untreated or treated with TIP-6. After treatment, cells were fixed in $70 \%$ ethanol at $-20^{\circ} \mathrm{C}$ overnight. Next, cells were washed with PBS and incubated in $25 \mathrm{ml}$ propidium iodide $(1 \mathrm{mg} / \mathrm{ml})$ (Bender MedStstems Inc., Burlingame, USA) and 5 $\mathrm{ml}$ DNase-free RNase $(10 \mathrm{mg} / \mathrm{ml}$ ) (Boehringer Mannheim, Mannheim, Germany) for $30 \mathrm{~min}$ at $37^{\circ} \mathrm{C}$ in the dark. Fluorescence was measured by Flow Cytometry (COLTER EPICS XL, USA) fitted with an air-cooled argon laser emitting at $488 \mathrm{~nm}$ and the data were collected and analyzed with CellQuest Pro (Becton Dickinson, San Jose, USA) and ModFit Lt Cell Cycle (Verity Software, Topsham, USA).

\subsection{Determination of Morphological Changes}

HepG2 and Hela cells $\left(1 \times 10^{6}\right.$ cells $)$ were seeded in a 6-chamber cell culture slide and were kept growing to their exponential phase. Cells were untreated or treated with TIP- 6 and washed with PBS twice. After wash, cells were incubated with $2 \mu \mathrm{M}$ DAPI, Annexin V/7-AAD (Beyotime Ltd., Nantong, China) for $1 \mathrm{~h}$ in the dark. Then cells were plated and fixed on a glass slide. The morphological features were examined by Olympus IX70 Fluorescent Inverted Microscope and photos were captured with Olympus DP70 Digital Camera System.

\subsection{Determination and Analysis of the Formation of Acidic Vesicular Organelles}

AO (Chroma Tech Inc., USA) was used for staining the cells following the instructions. Cells were incubated with DMEM containing TIP-6 at indicated concentration and 10\% FBS for $24 \mathrm{~h}$, followed by the addition of AO at a final concentration of $1 \mu \mathrm{l} / \mathrm{ml}$. After 15 min incubation, cells were washed with PBS three times. Then the fluorescence was measured the fluorescence with Eclipse Ti-U Inverted Fluorescence Microscope (Nikon Inc., Tokyo, Japan). Red fluorescence was observed with excitation and emission wavelength of $488 \mathrm{~nm}$ and $655 \mathrm{~nm}$, respectively. Images were captured with a CCD camera and processed with Photoshop (Adobe Systems Inc., San Jose, USA). Cells were also untreated or treated with 3-MA and fixed by 2.5 glutaraldehyde for $24 \mathrm{~h}$ on a glass slide. After dehydration, ultrathin sections were prepared using a Sorvall MT5000 microtome and collected on 150 mesh copper grids. At last, cells were stained with $1 \%$ uranyl acetate and/or lead citrate and images were captured with a JEOL 100CX transmission microscope camera.

\subsection{Western Blot}

Cells $\left(2 \times 10^{6}\right.$ cells) were untreated or treated with TIP- 6 at the indicated concentration for $24 \mathrm{~h}$ and washed twice with PBS before addition of the cell lysis 
buffer $(1 \times$ PBS, pH $8,1 \%$ Triton X-100) containing protease inhibitor (Sigma-Aldrich, Saint Louis, USA). Cell lysate $(30 \mu \mathrm{g})$ was loaded and separated by the $12 \%$ Bis-Tris gel. Proteins were subsequently transferred onto the nitrocellulose membrane (Bio-Rad Laboratories, Inc., California, USA). The membrane was blocked for $2 \mathrm{~h}$ in PBS supplemented with 5\% milk and 0.1\% Tween-20 (PBST) and incubated with primary antibody at $4^{\circ} \mathrm{C}$ overnight. The membrane was washed with PBST five times and incubated in horseradish peroxidase-conjugated secondary antibody for $1 \mathrm{~h}$ at room temperature. At last, the membrane was washed for $1 \mathrm{~h}$ with PBST and visualized using ECL detection reagents (Thermo Fisher Scientific, Waltham, USA). Primary antibodies, anti-LC3 (\#4108), anti-Bcl-2 (\#2872), anti-Beclin1 (\#3495), and anti- $\beta$-actin (\#4970) were purchased from Cell Signaling Technology (Beverly, MA, USA). Secondary antibodies, anti-rabbit (ZB-2308) were purchased from Zhongshan Golden Bridge Biotech, Inc. (Beijing, China).

\subsection{Molecular Modeling}

The atomic coordinates of Bcl-2 (PDB ID: 1YSW) and Bcl-xL (PDB ID: 3QKD) were obtained from Brookhaven Protein Data Bank. The structure of TIP-6 was built with Pymol and its topology was generated with PRODRG. The proteins were refined with Swiss PDB viewer, Pymol and Chimera. TIP-6 and proteins were minimized in SPC model water employing Steep Descent (SD) and Gromos 96 force field in the Gromacs 4.5 in each run, 10,000 steps were set for meeting the machine precision. Docking simulations were performed with AutoDock 4.2 using Lamrkain Genetic algorithm during which AutoDockTools (ADT) 1.5.4 was employed to prepare the proteins and ligands for docking calculations. Grid box was constructed with dimension set as $10 \times 60 \times 50$ points according to inhibitor binding site center (X: 15.47, Y: $-1.15, \mathrm{Z}: 1.37)$. All rotations and torsions for TIP- 6 were set as the default in the ADT.

\subsection{Statistical Analysis}

All data were expressed as mean \pm S.D. and analysis with Excel software. Every experiment was repeated at least three times. In each case, $\mathrm{P}$ value $<0.05$ was considered statistically significant.

\section{Results}

\subsection{Synthesis of Title Compound TIP-6}

Bridgehead nitrogen heterocycles are of interest because they are important building blocks of natural and unnatural products and many of them possess important biological activities. Saturated imidazo [1,2-a]pyridine ring systems have pharmacological properties such as antiviral [17] [18] [19], antimalarial [20], and antiulcer activities [21] [22]. Imidazo [1,2-a] pyridine moiety is also found in a wide range of natural products. For example, Oxaline [23] and Neoxaline [24] which were isolated from the culture broths of Penicillium species 
Fg-234 and Aspergillus japonicus Fg-551, respectively, were found to inhibit cell proliferation and arrest the cell cycle during $M$ phase in Jarkat cells [25]. Herein, TIP-6 was synthesized by an efficient four-component condensation reaction of benzaldehyde, acetophenone, and ethane-1,2-diamine in the presence of a catalytic amount of $p$-toluenesulfonic acid $\left(p-\mathrm{TsOH} \cdot \mathrm{H}_{2} \mathrm{O}\right)$ in methanol in high yield (Figure 1).

\subsection{The Inhibition of TIP- 6 on HepG2 Cell Viablibity}

Cell viability was expressed as a percentage of control and the IC50 represented the concentration of TIP- 6 at which the $50 \%$ of cells in each well were inhibited, and we got IC50 using GraphPad Prism. As expected, TIP-6 showed a significant inhibitory effect on cell viability (Figure 2) with an IC50 of $32.09 \mu \mathrm{M}$ with $24 \mathrm{~h}$ treatment. In the meantime, the same effect by TIP- 6 on Hela cells did not be observed.

\subsection{The Arrest of HepG2 Cells in G2/M-Phase}

With the significant inhibition effect of TIP-6 on HepG 2 cells viability was determined, the further examination of TIP- 6 on the cell cycle of HepG2 cells was performed by flow cytometry and the results were summarized in Table 1 . Results showed that TIP- 6 induced an arrest of G2/M phase in HepG2 cells manifested by an accumulation of cells in the portion of G2/M phase. Treatment with TIP-6 at $20 \mu \mathrm{M}, 40 \mu \mathrm{M}, 80 \mu \mathrm{M}$ and $160 \mu \mathrm{M}$ for $24 \mathrm{~h}$, the fraction of cells arrested in the G2/M phase were determined for $9.55 \%, 15.49 \%$, and $21.33 \%$ a significant increase compared to the fraction of cells in G2/M phase of the control $(7.02 \%)$. Meanwhile, a corresponding reduction of cells arrested in the G0/G1 phase was observed in cells treated with TIP-6.

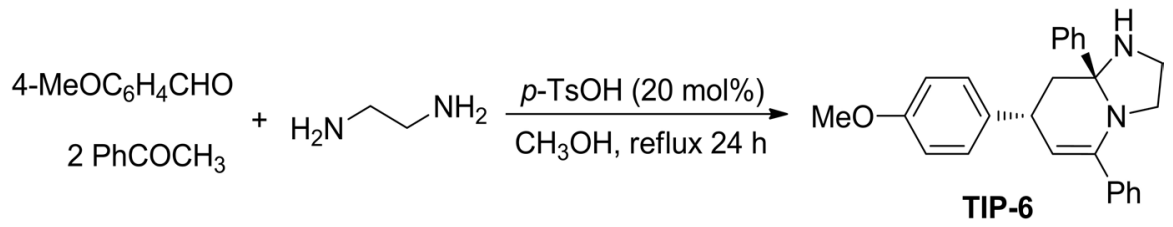

Figure 1. Synthetic diagram of TIP-6.
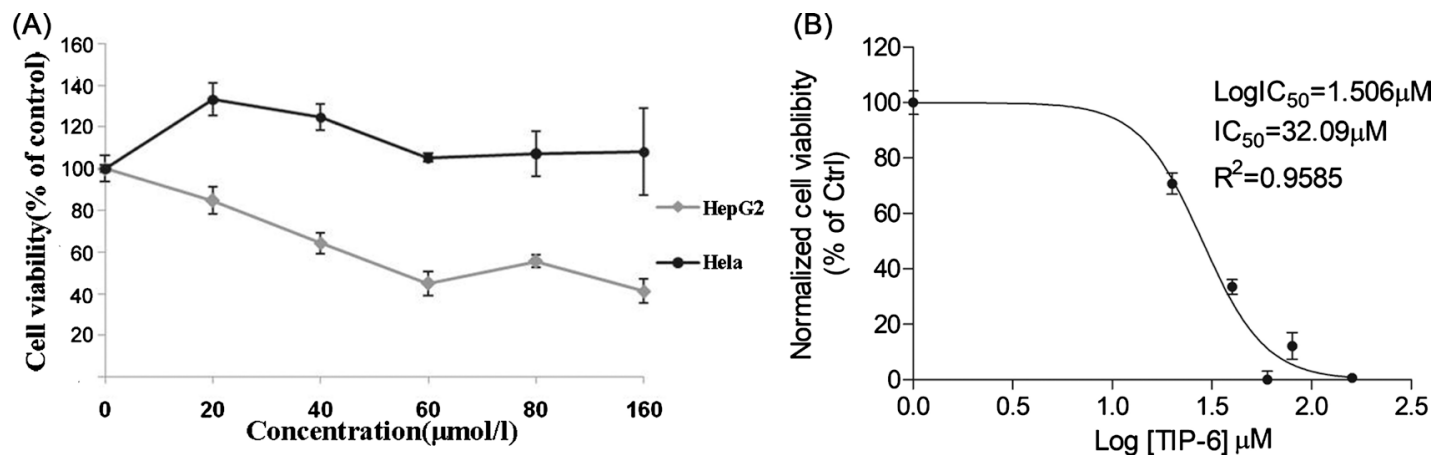

Figure 2. (A) Effect of TIP-6 on cell viability in HepG2 and Hela cells determined by MTT assay. (B) IC 50 value of HepG2 cells treated with TIP-6 was analyzed by GraphPad Prism. 


\subsection{Morphological Changes of HepG2 Cells Induced by TIP-6}

The examination of cell morphological changes was conducted, which are characteristics of autophagy in cells. Cells were treated with $150 \mu \mathrm{M}$ TIP-6 for $24 \mathrm{~h}$, it was failed to exhibit chromatin condensation and nuclear fragmentation,which are characteristics of canonical apoptosis and demonstrated by the staining of the cells with Annexin V/7-AAD (Figure 3(A)) and DAPI (Figure $3(\mathrm{~B}))$, respectively.

\subsection{The Formation of Autophagic Vacuoles and Accumulation of Acidic Vesicular Organelles in HepG2 Cells}

Cells were stained with the lysosomotropic reagent $\mathrm{AO}$ to assess the maturation of autolysosomes. It was clearly manifested that the presence of autolysosomes appeared after the treatment of TIP- 6 and the maturation of autolysosomes were indued by TIP-6 (Figure 4(A)). In addition, the Electron Microscope was

Table 1. Changes in cell phase of HepG2 cells treated with TIP-6 ( $\mathrm{n}=3, \bar{X} \pm S, \%)$.

\begin{tabular}{cccc}
\hline Concentration $(\mu \mathrm{M})$ & G0/G1 & $\mathrm{S}$ & $\mathrm{G} 2 / \mathrm{M}$ \\
\hline 0 & $62.89 \pm 1.97$ & $30.09 \pm 1.93$ & $7.02 \pm 0.87$ \\
40 & $59.21 \pm 2.13$ & $31.24 \pm 1.65$ & $9.55 \pm 1.91$ \\
80 & $53.82 \pm 1.89$ & $30.69 \pm 2.25$ & $15.49 \pm 1.79^{*}$ \\
160 & $48.96 \pm 1.71^{*}$ & $29.71 \pm 1.83$ & $21.33 \pm 2.17^{\star *}$ \\
\hline
\end{tabular}

${ }^{\star} \mathrm{P}<0.05$ vs $0 \mu \mathrm{M},{ }^{* *} \mathrm{P}<0.01$ vs $0 \mu \mathrm{M}$.
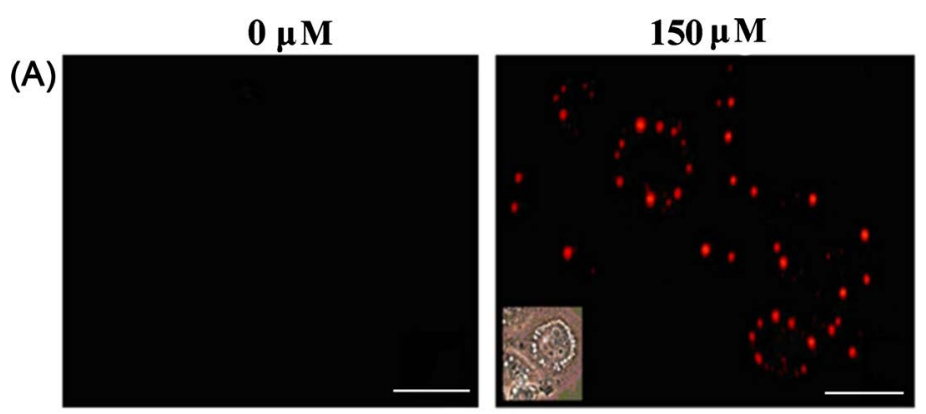

(B)
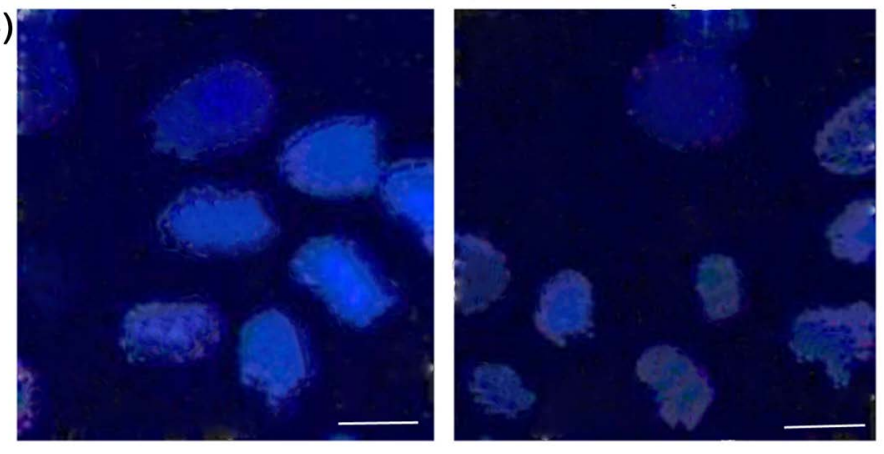

Figure 3. Annexin V/7-AAD and DAPI immunofluorescence staining analysis. HepG2 cells untreated or treated with TIP-6 for 24 hours. (A) The fluorescence staining with Annexin V/7-AAD. (COOPLIX P5100, Nikon). (B) The fluorescence staining with DAPI. (COOPLIX P5100, Nikon). Scale bar, $30 \mu \mathrm{m}$. 


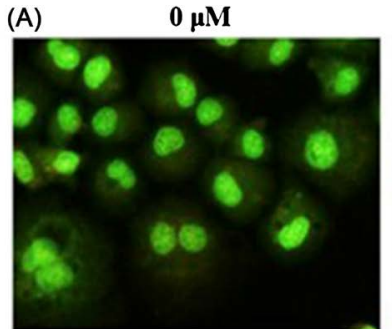

(B)

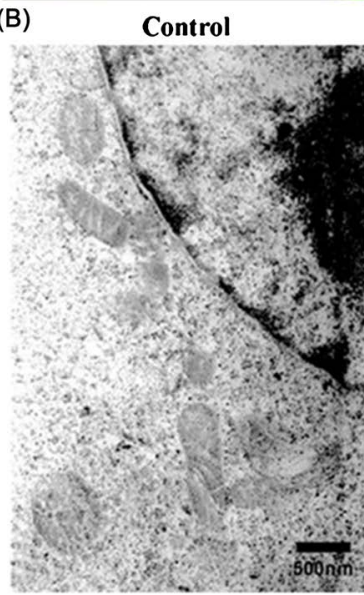

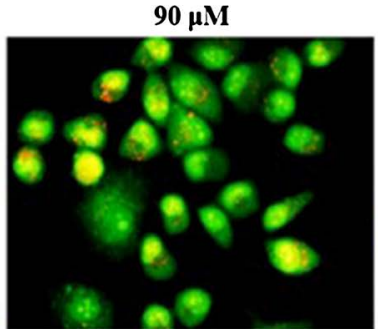

TIP-6

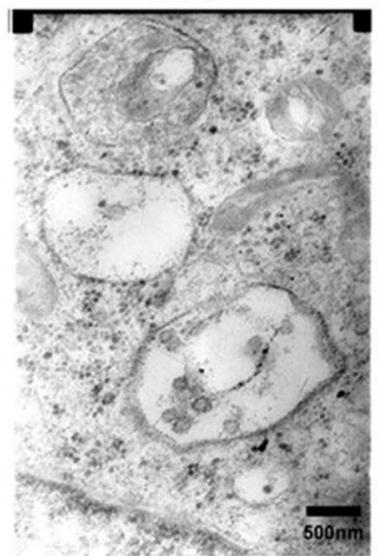

$150 \mu \mathrm{M}$

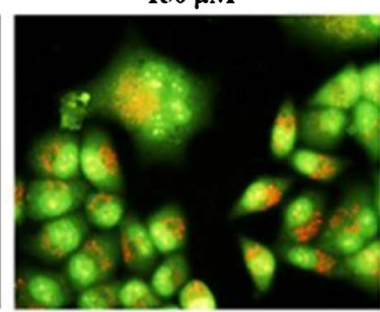

TIP-6+3-MA

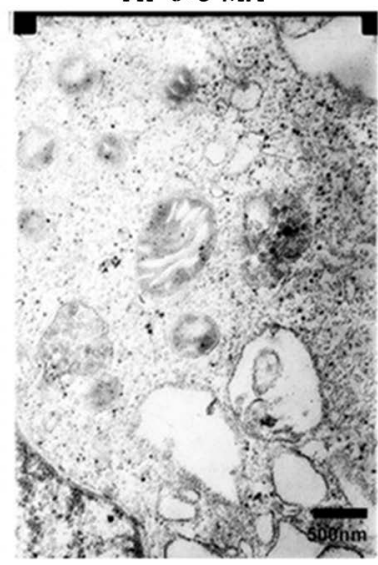

Figure 4. Analysis of autophagic vacuoles and sub-microstructure after treated HepG2 cell with TIP-6. HepG2 cells treated with different concentration of TIP-6 for $24 \mathrm{~h}$. (A) The formation of autophagic vacuoles. ( $\times 20$, COOPLIX P5100, Nikon). (B) The sub-microstructural analysis with transmission electron microscope.

employed to confirm the formation of vacuoles and to visualize the contained material in the autophagic vacuoles. As shown in (Figure 4(B)), well-shaped vacuoles were formed in HepG2 cells treated with $90 \mu \mathrm{M}$ TIP-6 for $24 \mathrm{~h}$, and it was in stark comparison to the control in which HepG2 cells exposed with 90 $\mu \mathrm{M}$ TIP-6 and $10 \mu \mathrm{M}$ 3-MA (3-methyladenine).

\subsection{The Effect of TIP-6 on the Expression of Autophagy-Related Proteins}

LC3, a mammalian homolog of yeast Atg8, is the only reliable marker of autophagosomes, and Beclin-1 is also a mammalian ortholog of the yeast Atg6. This protein interacts with either BCL-2 or PI3K class III, playing a major role in the regulation of both autophagy and cell death. The protein levels of Bcl-2 and LC3 were detected by western blot. Expectedly, the results showed that LC-3 I/II and Beclin1 were up-regulated, while Bcl-2 was down-regulated (Figure 5).

HepG2 cells were treated with different concentrations of TIP- 6 for $24 \mathrm{~h}$, and $30 \mu \mathrm{g}$ of total protein was used to detect the interested proteins.

\subsection{Modeling of the Binding of TIP- 6 to Bcl-2 and Bcl-xL}

Since the autophagy is initiated under certain circumstances when apoptosis is blocked, it suggested that TIP-6 may bind to Bcl-2 and Bcl-xL, two well-known major apoptosis regulators, and compromise their activity. The authors per- 
formed the molecular docking of TIP-6 to Bcl-2 and Bcl-xL. The available X-ray structures of Bcl-2 and Bcl-xL coordinated to individual ligands were used as a positive control to validate docking reliability [26] [27]. The binding mode of each ligand to relevant protein was highly consistent with the original binding mode present in the structure obtained from co-crystallization (Figure 6). As

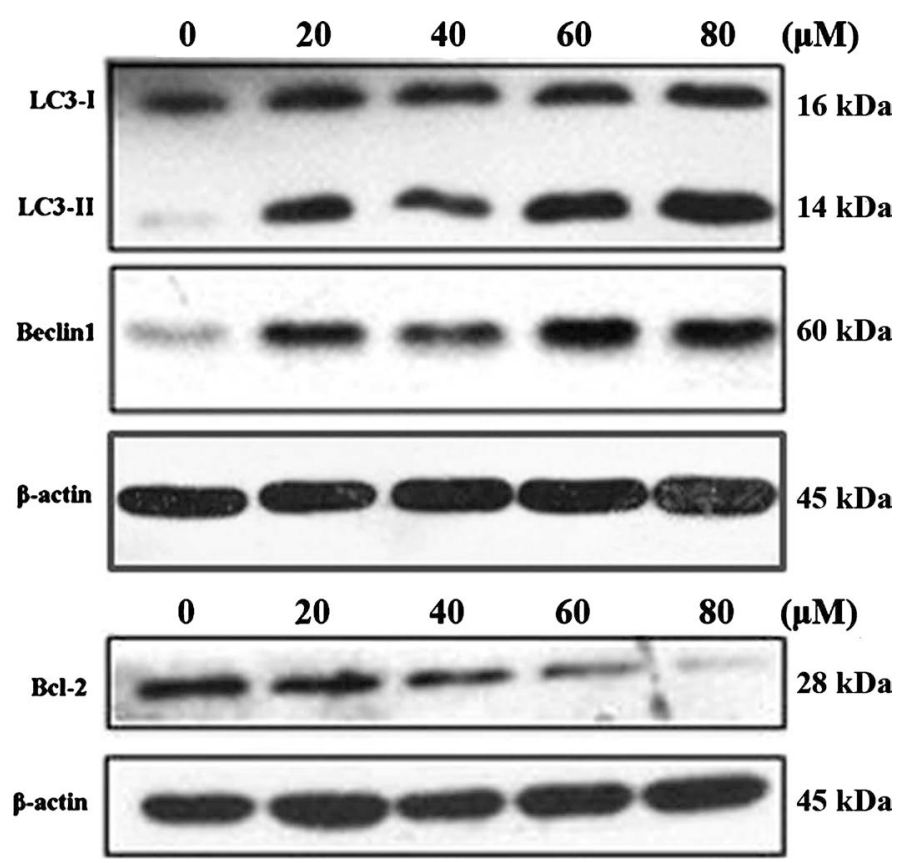

Figure 5. Western blot analysis of the effect of TIP-6 on the expression of autophagy-related proteins.

(A) (a)
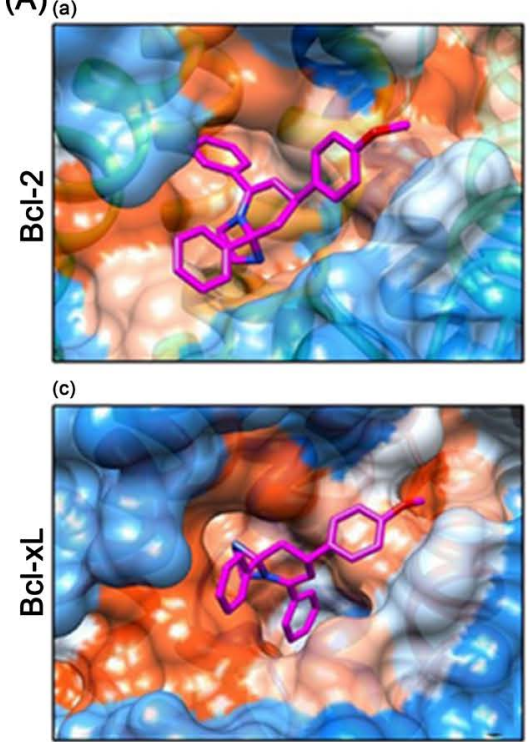

(b)

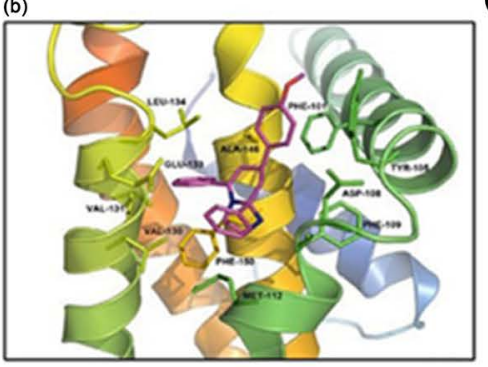

(d)

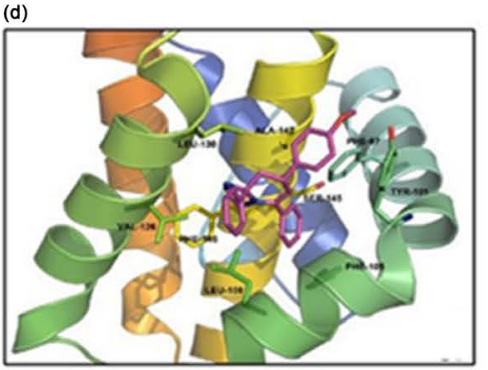

(B) (a)
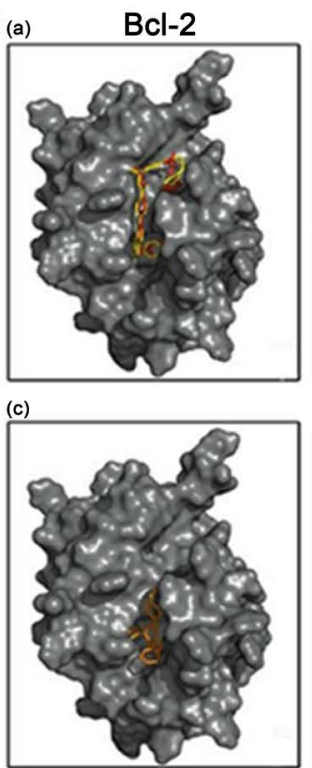
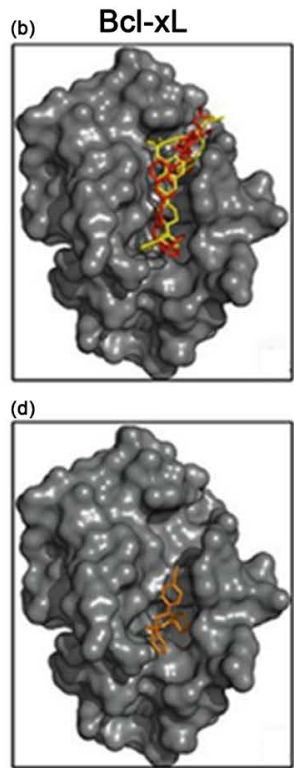

Figure 6. Models of TIP-6 bind to Bcl-2 and Bcl-xL. (A) ((a), (c)) TIP-6 bind to the pocket of the initial inhibitors binding site in Bcl-2 and Bcl-xL. The pocket was shown in electrostatic potentials; ((b), (d)) Orientation of TIP-6 in the active binding site was shown the main residues. (B) ((a), (b)) Overlay of redocked inhibitors (carbon atoms in red) and crystal inhibitors (carbon atoms in yellow) at the active site of Bcl-2/Bcl-xL using the Pymol program. ((c), (d)) The predicted orientation of TIP-6 within the BH-3 binding groove of $\mathrm{Bcl}-2 / \mathrm{Bcl}-\mathrm{xL}$. 
the molecular docking of ligands of $\mathrm{Bcl}-2$ and $\mathrm{Bcl}-\mathrm{xL}$ was validated and proved effective and reliable, then the docking was conducted with TIP-6 to Bcl-2 and $\mathrm{Bcl}-\mathrm{xL}$, respectively. The data showed that TIP-6 binds to Bcl-2 and Bcl-xL at their active sites. The binding region was a hydrophobic pocket which was occupied by original ligand in either Bcl-2 or Bcl-xL. The binding free energy for TIP-6 to Bcl-2 and Bcl-xL was $-8.0 \mathrm{kcal} / \mathrm{mol}$ and $-8.4 \mathrm{kcal} / \mathrm{mol}$, whereas the binding free energy for original inhibitor to Bcl-2 and Bcl-xL is $-9.39 \mathrm{kcal} / \mathrm{mol}$ and $-9.22 \mathrm{kcal} / \mathrm{mol}$, indicating that TIP-6 has more efficient or less efficient binding ability.

\section{Discussion}

The designed and synthesized TIP- 6 which exhibited an anti-proliferative effect in HepG2 cell line, and promoted the cell death of HepG2 cells in an autophagy cell death fashion. As the cell viability of TIP- 6 was more obvious in HepG2 cells than that in Hela cells, HepG2 cells were used to characterize the bio-activity of TIP-6. The analysis of cell cycle by flow cytometry showed that HepG2 cells were arrested in G2/M phase after treating with TIP-6, manifested by a significant increase in the proportion of $\mathrm{G} 2 / \mathrm{M}$ phase (from $7.02 \%$ to $21.33 \%$ ) and a corresponding decrease in proportion of G0/G1 phase (from $62.89 \%$ to $48.96 \%$ ) while the proportion of $S$ phase remained relatively stable. Treatment of HepG2 cells with TIP-6 resulted in the accumulation of cells in G2/M phase, ultimately comprising the passage of cells into $M$ phase and inhibiting the cell viability.

The cell morphological changes and DAPI fluorescent staining showed that HepG2 cells failed to exhibit morphological changes that are characteristics of apoptosis, including condensation of nuclei, shrinkage of the cytoplasm, the convolution of outlines, and detachment from the surrounding tissue, when cells were treated with TIP-6. Also, the exposure of phosphatidylserine by staining of Annexin-V/7-AAD wasn't detected. AO was used to detect the presence of acidic vacuoles characteristic of the autophagy cell death. The cell death initiated by TIP-6 was effectively inhibited by pre-treatment of HepG2 cells with 3-MA, confirming that the autophagic cell death was initiated in HepG2 cells by treatment with TIP-6.

Autophagy is a dynamic self-degradation process undertaken in cells either in healthy state or disease state which nevertheless involves a lysosomal degradation pathway [28]. The formation of autophagosome that sequesters intracellular components for degradation in lysosomes involves two steps, the nucleation and assembly of the initial phagophore membrane and the elongation and expansion of membrane, of which the steps are characteristic of the expression of Beclin1 and LC3, respectively [29] [30]. It was demonstrated that Bcl-2 antiapoptotic proteins inhibited autophagy and hypothesized that $\mathrm{Bcl}-2$ functions coordinated to Beclin1 to inhibit the Beclin1-dependent autophagy [31]. It was found that the expression of Bcl-2 decreased while the expression of Beclin1 and LC3-II/LC3-I increased in the same manner in HepG2 cells treated with TIP-6. 
A number of small molecules had been reported capable of inhibiting the activities of Bcl-2 antiapoptotic proteins and promoting the autophagy in cancer cells [32]. These promising results prompted us to explore whether the TIP-6 employs a similar mode which bind to Bcl-2 antiapoptotic proteins in initiating and promoting the autophagy. The molecular docking assessed the binding affinity between TIP- 6 and Bcl-2 or Bcl-xL. It was found that an appreciable high score in the binding mode of which the TIP- 6 was well docked in the Bcl-2 active site. These indicated that TIP-6 initiated and promoted the autophagy in HepG2 cells by interacting with Bcl-2 antiapoptotic proteins.

In summary, the authors designed and synthesized TIP- 6 which had pronounced anti-proliferative activity in HepG2 cells. In addition, TIP- 6 exerted its anti-proliferative effect through effectively initiating and promoting the autophagy. This study provides a promising small molecule targeting autophagy and Bcl-2 may play a positive role in the initiation of HepG2 cell autophagy by TIP-6. Meanwhile, further investigations are needed to elucidate its role and potential anti-cancer effect in other types of cancer.

\section{Conclusion}

In this study, it was demonstrated that TIP-6 inhibited HepG2 cell proliferation, and this may due to the induced autophagy. Further investigations showed that TIP-6 down-regulated Bcl-2 and up-regulated PI3K class III, which plays a major role in the regulation of autophagy. And the most interesting is that docking showed that TIP- 6 may bind in the Bcl-2 active site. Unfortunately, we are unable to determine from these data to make sure that TIP-6 binds with Bcl-2, so more experiments need to be performed in the future.

\section{Acknowledgements}

This work was supported by the Gansu Provincial Science and Technology plan Project (No. 0708NKCA124) of China.

\section{Conflicts of Interest}

The authors declare no conflicts of interest regarding the publication of this paper.

\section{References}

[1] Guo, J.Y., Xia, B. and White, E. (2013) Autophagy-Mediated Tumor Promotion. Cell, 155, 1216-1219. https://doi.org/10.1016/j.cell.2013.11.019

[2] Kroemer, G., Marino, G. and Levine, B. (2010) Autophagy and the Integrated Stress Response. Molecular Cell, 40, 280-293. https://doi.org/10.1016/j.molcel.2010.09.023

[3] Wang, D.W., et al. (2015) The Different Roles of Selective Autophagic Protein Degradation in Mammalian Cells. Oncotarget, 6, 37098-37116.

[4] Mizushima, N. and Levine, B. (2010) Autophagy in Mammalian Development and Differentiation. Nature Cell Biology, 12, 823-830. https://doi.org/10.1038/ncb0910-823 
[5] Mizushima, N., et al. (2008) Autophagy Fights Disease through Cellular Self-Digestion. Nature, 451, 1069-1075. https://doi.org/10.1038/nature06639

[6] Shintani, T. and Klionsky, D.J. (2004) Autophagy in Health and Disease: A Double-Edged Sword. Science, 306, 990-995.

https://doi.org/10.1126/science.1099993

[7] Anding, A.L. and Baehrecke, E.H. (2015) Autophagy in Cell Life and Cell Death. Current Topics in Developmental Biology, 114, 67-91. https://doi.org/10.1016/bs.ctdb.2015.07.012

[8] Altman, B.J. and Rathmell, J.C. (2009) Autophagy: Not Good OR Bad, But Good and Bad. Autophagy, 5, 569-570. https://doi.org/10.4161/auto.5.4.8254

[9] Bhutia, S.K., et al. (2013) Autophagy: Cancer's Friend or Foe? Advances in Cancer Research, 118, 61-95. https://doi.org/10.1016/B978-0-12-407173-5.00003-0

[10] Kimmelman, A.C. (2011) The Dynamic Nature of Autophagy in Cancer. Genes \& Development, 25, 1999-2010. https://doi.org/10.1101/gad.17558811

[11] Maycotte, P. and Thorburn, A. (2011) Autophagy and Cancer Therapy. Cancer Biology \& Therapy, 11, 127-37. https://doi.org/10.4161/cbt.11.2.14627

[12] Klionsky, D.J., et al. (2003) A Unified Nomenclature for Yeast Autophagy-Related Genes. Developmental Cell, 5, 539-545. https://doi.org/10.1016/S1534-5807(03)00296-X

[13] Maiuri, M.C., et al. (2009) Control of Autophagy by Oncogenes and Tumor Suppressor Genes. Cell Death and Differentiation, 16, 87-93. https://doi.org/10.1038/cdd.2008.131

[14] Lee, J.S., et al. (2013) Anti-Cell Death Engineering of CHO Cells: Co-Overexpression of Bcl-2 for Apoptosis Inhibition, Beclin-1 for Autophagy Induction. Biotechnology and Bioengineering, 110, 2195-207. https://doi.org/10.1002/bit.24879

[15] Lindqvist, L.M., et al. (2014) Prosurvival Bcl-2 Family Members Affect Autophagy Only Indirectly, by Inhibiting Bax and Bak. Proceedings of the National Academy of Sciences of the United States of America, 111, 8512-8517. https://doi.org/10.1073/pnas.1406425111

[16] Zhang, X.-Q., et al. (2010) Apogossypolone, a Novel Inhibitor of Antiapoptotic Bcl-2 Family Proteins, Induces Autophagy of PC-3 and LNCaP Prostate Cancer Cells in Vitro. Asian Journal of Andrology, 12, 697-708. https://doi.org/10.1038/aja.2010.57

[17] Gueiffier, A., Lhassan, M., et al. (1996) Synthesis of Acyclo-C-nucleosides in the Imidazo[1,2-a]pyridine and Pyrimidine Series as Antiviral Agents. Journal of Medical Chemistry, 39, 2856-2859. https://doi.org/10.1021/jm9507901

[18] Gueiffier, A., et al. (1998) Synthesis of Imidazo[1,2-a]pyridines as Antiviral Agents. Journal of Medical Chemistry, 41, 5108-5112. https://doi.org/10.1021/jm981051y

[19] Gudmundsson, K.S., et al. (1997) Synthesis and Antiviral Activity of Certain 5'-Modified Analogs of 2,5,6-Trichloro-1-(beta-D-ribofuranosyl)benzimidazole. Journal of Medical Chemistry, 40, 785-793. https://doi.org/10.1021/jm9604888

[20] Srivastava, P., Pandey, V.C., Misra, A.P., Gupta, P., Raj, K. and Bhaduri, A.P. (1998) Potential Inhibitors of Plasmodial Heme Oxygenase; an Innovative Approach for Combating Chloroquine Resistant Malaria. Bioorganic \& Medicinal Chemistry, 6, 181-187. https://doi.org/10.1016/S0968-0896(97)10013-X

[21] Kaminski, J.J. and Doweyko, A.M. (1997) Antiulcer Agents. 6. Analysis of the in Vitro Biochemical and in Vivo Gastric Antisecretory Activity of Substituted Imidazo[1,2-a]pyridines and Related Analogues Using Comparative Molecular Field 
Analysis and Hypothetical Active Site Lattice Methodologies. Journal of Medical Chemistry, 40, 427-436. https://doi.org/10.1021/jm950700s

[22] Kaminski, J.J., et al. (1989) Antiulcer Agents. 4. Conformational Considerations and the Antiulcer Activity of Substituted Imidazo[1,2-a]pyridines and Related Analogues. Journal of Medical Chemistry, 32, 1686-1700. https://doi.org/10.1021/jm00128a005

[23] Steyn, P.S. (1970) The Isolation, Structure and Absolute Configuration of Secalonic Acid D, the Toxic Metabolite of Penicillium oxalicum. Tetrahedron, 26, 51-57. https://doi.org/10.1016/0040-4020(70)85006-2

[24] Hirano, A., Iwai, Y., Masuma, R., Tei, K. and Omura, S. (1979) Neoxaline, a New Alkaloid Produced by Aspergillus Japonicus. Production, Isolation and Properties. Journal of Antibiotics (Tokyo), 32, 781-785.

[25] Koizumi, Y., Arai, M., Tomoda, H. and Ōmura, S. (2004) Oxaline, a Fungal Alkaloid, Arrests the Cell Cycle in M Phase by Inhibition of Tubulin Polymerization. Biochimica et Biophysica Acta, 1693, 47-55. https://doi.org/10.1016/j.bbamcr.2004.04.013

[26] Muchmore, S.W., et al. (1996) X-Ray and NMR Structure of Human Bcl- $\mathrm{x}_{\mathrm{L}}$, an Inhibitor of Programmed Cell Death. Nature, 381, 335-341. https://doi.org/10.1038/381335a0

[27] Vance, B.A., Zacharchuk, C.M. and Segal, D.M. (1996) Recombinant Mouse Bcl-2(1-203). Two Domains Connected by a Long Protease-Sensitive Linker. Journal of Biological Chemistry, 271, 30811-30815. https://doi.org/10.1074/jbc.271.48.30811

[28] Levine, B. and Kroemer, G. (2008) Autophagy in the Pathogenesis of Disease. Cell, 132, 27-42. https://doi.org/10.1016/j.cell.2007.12.018

[29] He, C. and Klionsky, D.J. (2009) Regulation Mechanisms and Signaling Pathways of Autophagy. Annual Review of Genetics, 43, 67-93. https://doi.org/10.1146/annurev-genet-102808-114910

[30] Mizushima, N. (2004) Methods for Monitoring Autophagy. The International Journal of Biochemistry \& Cell Biology, 36, 2491-2502. https://doi.org/10.1016/j.biocel.2004.02.005

[31] Pattingre, S., et al. (2005) Bcl-2 Antiapoptotic Proteins Inhibit Beclin 1-Dependent Autophagy. Cell, 122, 927-939. https://doi.org/10.1016/j.cell.2005.07.002

[32] Oltersdorf, T., et al. (2005) An Inhibitor of Bcl-2 Family Proteins Induces Regression of Solid Tumours. Nature, 435, 677-681. https://doi.org/10.1038/nature03579 